\title{
MANAJEMEN KOMUNIKASI PENDIDIKAN MULTIKULTURAL MENUJU PENDIDIKAN DAMAI DAN TOLERANSI
}

\author{
Mustaqim \\ Fakultas Ilmu Tarbiyah dan Keguruan Universitas Islam Negeri Walisongo Semarang \\ Jl. Prof. Dr. Hamka, Tambakaji, Kota Semarang, Jawa Tengah \\ mustaqimsamadi@yahoo.com
}

\begin{abstract}
The focus of this research is on management of educational communication in enhancing the attitude of multiculturalism, both communication management at the class and faculty level. This research approach is qualitative with descriptive analytic type, while the techniques of collecting data are observation, interview and documentation as well as a closed questionnaire specifically for multiculturalism attitude data. Data analysis techniques using Milles and Huberman patterns, namely data reduction, data presentation and conclusion drawing, specifically the data of multiculturalism attitude analyzed quantitative descriptive. The results of this study found that multicultural education communication management strategies include the educational system, communicator credibility, communication processes in learning / lectures, educational institution culture, content of teaching materials, communicant attitudes, multiculturalism values, and the involvement of all social education environments. $78 \%$ have a multicultural attitude towards the civitas and alumni in supporting the application of multiculturalism values. This is supported by internal factors, namely educational communicators, messages in the form of lecture materials related to multiculturalism, culture or campus climate which intersect with multiculturalism. While external factors, including: Balinese culture and habits of interaction between Balinese with foreign cultures.
\end{abstract}

Keywords: Communication Management, Education, Multicultural

\begin{abstract}
Abstrak
Fokus penelitian ini mengenai manajemen komunikasi pendidikan dalam meningkatkan sikap multikulturalisme, baik pada level kelas maupun Fakultas. Pendekatan yang digunakan kualitatif dengan jenis deskriptif analitik, sedang teknik pengumpulan data observasi, wawancara dan dokumentasi serta angket tertutup khusus untuk data sikap multikulturalisme. Teknik analisis data menggunakan pola Milles dan Huberman: reduksi data, penyajian data dan penarikan kesimpulan, khusus data sikap multikulturalisme dianalisis deskriftif kuantitatif. Hasil penelitian ini menemukan strategi manajemen komunikasi pendidikan multikultur mencakup sistem pendidikan, kredibilitas komunikator, proses komunikasi dalam perkuliahan, budaya lembaga pendidikan, konten bahan ajar, sikap komunikan, nilai multikulturalisme, serta keterlibatan semua lingkungan sosial pendidikan. Sebesar 78\% memiliki sikap multikultural sikap civitas dan alumni dalam mendukung penerapan nilai multikulturalisme. Hal ini didukung oleh faktor internal yakni komunikator pendidikan, pesan yang berupa materi perkuliahan berkaitan dengan multikulturalisme, budaya atau iklim kampus yang beririsan dengan multikulturalisme. Faktor eksternal, meliputi budaya masyarakat Bali serta kebiasaan interaksi masyarakat Bali dengan budaya asing.
\end{abstract}

Kata Kunci: Manajemen Komunikasi, Pendidikan, Multikultural 


\section{PENDAHULUAN}

$\begin{aligned} & \text { Sikap multikultural } \\ & \text { yang }\end{aligned} \begin{array}{r}\text { merupakan } \\ \text { membentuk } \\ \text { indikator } \\ \text { memponen }\end{array}$
$\begin{aligned} & \text { kemajemukan. Empati: } \\ & \text { kemajemukan }\end{aligned}$
$\begin{aligned} & \text { ideologis/kepercayaan, kemajemukan } \\ & \text { politis, kemajemukan kultural dan } \\ & \text { kemajemukan kelas sosial/stratifikasi }\end{aligned}$
(Wirutomo, dkk, 2012:20). Sebaran
kemajemukan di Indonesia sifatnya tidak
merata lebih dari 41,7\% dominasi suku
jawa, dari segi agama 88,22\% beragama
Islam. Persebaran penduduk yang
bermukin di pulau jawa 59\% yang luasnya
hanya 6\%. Secara sosiologis, penyebaran
penduduk yang tidak merata dan tidak
seimbang jumlahnya antar kelompok, ini
pasti akan mempengaruhi proses integrasi
dari bangsa ini (Wirutomo, dkk, 2012:291-
292).

(2007:266)

komunikasi antar budaya yang berdasarkan orientasi diri (self oriented) dapat mengubah efektifitas komunikasi menjadi komunikasi disfungsional. Sehingga sebuah komunikasi harus memiliki efektifitas yang tinggi dalam menyokong sebuah kemajemukan dan keberagaman. Keberhasilan komunikasi dalam keberagaman ditegarai dari masyarakat majemuk yang memiliki segmentasi kelompok dengan sub kebudayaan, struktur sosial bersifat nonkomplementer, adanya konsesus terhadap nilai dasar, konflik antar kelompok, integrasi sosial tumbuh di atas paksaan (coercion) dan saling ketergantungan di dalam bidang ekonomi serta dominasi politik (Kartadinata, 2015: 95).

Kekerasan komunal di Indonesia, mencapai $89,3 \%$ dibanding dengan kekerasan lain dimana kekerasan meliputi antar kelompok etnis, pemeluk agama, aliran/kelompok dalam agama yang sama (Suaedy, dkk, 2007: 344). Penyebab konflik juga bisa disebabkan oleh faktor identitas dan distribusi (Harris dan Reily, 2000: 354). Pola konflik yang didasarkan atas identitas primordialisme adalah pola konflik yang mendalam dan paling sulit diselesaikan. Sedang yang dimaksud "Distribusi" adalah pembagian sumber daya ekonomi dan politik yang tidak merata diantara kelompok-kelompok kepentingan dalam kelompok identitas tersebut.

Faktor lain yang mempengaruhi turunnya kualitas toleransi adalah globalisasi, yang menyuburkan faham individualisme dan menurunnya Grouporiented (Behman, 2017: 5). Indonesia sebagai bagian dari masyarakat plural Asia Tenggara, dapat terjerumus ke dalam anarki, jika gagal menemukan formula federasi pluralis yang memadai (Mahfud, 2006: 84). Sehingga perlu strategi yang unik oleh kelompok maupun individual atau lembaga pendidikan untuk meningkatkan kualitas sikap multikultural meminimalkan konflik.

Peristiwa yang bernuansa non multikultural juga pernah terjadi di Bali, seperti: bentrokan antara Laskar Bali dg Baladika (tempo, 2015); bentrok massa dua anggota dari dua organisasi massa terbesar di Bali (sindonews.com, 2017); tawuran antar warga kabupaten Bangli (VIVANews, 2011); bentrokan antar pelajar SMAN 4 dengan SMAN 1(NusaBali.Com, 2017). Pada waktu yang hampir bersamaan di Denpasar Bali muncul kegiatan para mahasiswa sebagai indicator munculnya kesadaran sikap multicultural "Deklarasi Merajut Kebangsaan" mengususng multikulturalisme dan toleransi (Antaranews Bali, 2018).

Manajemen merupakan proses integrase sumber menjadi sistem total untuk menyelesaikan suatu tujuan (Pidarta, 2004: 4). Konsep tersebut bersumber dari Follet (1997) bahwa manajemen adalah 
seni untuk menghadapi orang. Saefullah (2006:5) meringkasnya menjadi manajemen adalah ilmu dan seni, didalamnya ada kreatifitas dan pengalaman yang menjadi faktor pembeda antar manajer.

Makna Pendidikan Multikultural, yaitu: interethnic education, transcultural education, multiethnic education, dan cross-cultural education, sedang Driel menambahkan human right education dan intercultural education, UNESCO memperkenalkan istilah lain, yaitu inclusive education (Aly, 2010:103). Pendidikan multikultural dapat diartikan sebagai pendidikan mengenai keragaman kebudayaan. Dalam Mahfud, (2006: 167), Pendidikan multikultural adalah "konsep pendidikan yang memberikan kesempatan yang sama kepada semua peserta didik, tanpa memandang gender dan kelas social, etnik, ras, agama, dan karakteristik cultural mereka untuk belajar didalam kelas.

Pendidikan multikultural dan kaitannya dengan komunikasi terletak pada proses penyampaian pesan dan penerimaannya secara kompleks dan beragam dan merefleksikan pentingnya budaya, ras, seksualitas dan gender, agama, status sosial, ekonomi, dan pengecualian dalam proses pendidikan. Sehingga menggabungkan komunikasi, dan multikulturalisme sebagai politic of recognition yakni pengakuan terhadap identitas kelompok yang berbeda dan diterimanya perbedaan (Mahfud, 2006: 168).

Manajemen pendidikan bisa dilakukan mulai dari entitas kecil di ranah sekolah maupun perguruan tinggi. Model pendidikan multikultural mengintegrasikan antara pendidikan, manajemen dan komunikasi dalam rangka mereduksi perbedaan sosial, ekonomi, dan budaya sehingga muncul konsep komunikasi kependidikan (Murad, 2014). Konsep pendidikan meliputi pola manajemen kelas seperti hasil penelitian antar negara instruktur Amerika cenderung fokus pada interaksi peserta didik, adapun instruktur Korea menekankan pada interaksi guru dengan peserta didik (Yoo, dkk, 2014). Sedangkan di Indonesia kemampuan guru dalam mengelolah kelas penting (Ritu, 2014). Penelitian yang mendukung konsep tersebut kemampuan guru lebih dominan pada pemanfaatan teknologi modern, pendekatan-pendekatan pendidikan multikultural, dan merespon isu-isu keadilan yang adil (Blythe, dkk, 2014).

Perhatian dan perlakuan terhadap siswa yang memilki perbedaan harus,seperti diungkapkan oleh Hecht (2014) Pendidikan harus memperhatikan semua etnis, budaya, kota, pedesaan, pinggiran, pribumi dan migran. Hal seirama juga disampaikan oleh Maydosz (2014) bahwa pendidikan harus tidak membedakan antar ras, Amerika atau keturunan Afrika, minoritas atau mayoritas (Gasman \& Commodore, 2014).

Manajemen komunikasi pendidikan berbentuk proses komunikasi antara pihak sekolah dengan internal dan eksternalnya (Xu, Hao \& Huennekens, 2016). Seperti mislanya desain dari sekolah belum tentu baik dan relevan, seperti temuan Somaraki dalam penelitiannya, bahwa perilaku anak dari ibu keturunan Swedia dibandingkan dengan perilaku anak dari ibu keturunan non Swedia berbeda karena ada perbedaan pembiasaan oleh ibu, dengan kata lain pembiasaan ibu mempengaruhi perilaku anak-anaknya (Somaraki, dkk, 2016).

Salah satu model peningkatan kemampuan guru dalam manajemen komunikasi antar budaya dengan upaya sistemik melalui peningkatan kualitas komunikator dalam hal pengetahuan di bidang praktik mengajar dari beragam latar belakang budaya dan fungsional dan 
memupuk kolaborasi di antara sekolah dan keluarga (Cousik, 2015).

Hasil penelitian Sunu, dkk (2014) menunjukkan keharmonisan hubungan antara desa dinas dan desa pakraman. Praktik harmonisasi sosial yang dilakukan adalah umat Hindu maupun umat lain yang ada dalam wilayah desa pakraman bersama-sama menciptakan integrasi atas dasar toleransi dan kerukunan serta saling menghormati dalam rangka membina rasa persatuan dan kesatuan masyarakat Bali.

Penelitian lain dilakukan oleh Prami (2014) konflik adat yang terjadi di Bali dipengaruhi oleh perbedaan pemahaman terhadap aturan yang berlaku bagi masyarakat adat. Konflik adat yang terjadi di Bali dipengaruhi oleh tumpang tindihnya pelaksanaaan antara pemerintahan desa adat dengan desa dinas (secara administrasi). Kondisi inilah yang menimbulkan salah tafsir dalam masyarakat. Untuk menjembatani konflik masyarakat di Bali Windia (2010) perlu menumbuhkan keharmonisan dan penanaman nilai multikultur dan toleransi. Sebab, konflik tersebut menimbulkan citra negatif terhadap Bali yang sudah dikenal di dunia internasional sebagai tujuan wisata.

Lebih lanjut, penelitian Gillas (2002) dan Vedder dan Veendrick (2003) menyimpulkan bahwa pembelajaran dengan Cooperative Learning mempengaruhi terhadap lahirnya sikap toleransi dan penerimaan yang lebih luas dan dapat mendukung terciptanya hubungan yang lebih baik antara siswa berbeda ras dan etnis. Menurut penelitian Sharan dkk (1984-1999) menghasilkan kesimpulan bahwa Cooperatif Learning menghasilkan lebih banyak perilaku kooperatif, baik komunikasi verbal maupun nonverbal dibandingkan dengan pengajaran "Seluruh Kelas" siswa-siswa dalam kelas cooperative learning menunjukkan lebih sedikit perilaku kompetitif dan lebih banyak kerjasama lintas-etnis (Arends, 2008: 9). Pada sekolah yang beragam secara budaya, bisa meningkatkan kapasitas sekolah untuk melibatkan dan menyertakan anak-anak dari keluarga yang berlatar belakang migran. Pada sekolah yang kurang beragam, sekolah bisa mengajar anak-anak tentang keragaman budaya (Block, Gibbs \& Townsend, 2015).

Jika ditarik kesimpulan atas dasar kemiripan manajemen multikultural maka bisa digolongkan dengan Teori Sistem, yaitu Sekumpulan bagian-bagian yang saling terkait dengan saling bergantung antara satu dengan lainnya, yang oleh manajer ditata sedemikian rupa hingga membentuk sebuah kesatuan yang utuh (Robbins dan Judge, 2008).

\section{METODE PENELITIAN}

Pendekatan penelitian ini adalah kualitatif dengan jenis deskriptif analitik, yang akan menghasilkan data tentang manajemen pendidikan multikultural. Lokasi penelitian ini dilakukan di Fakultas Dharma Acarya Institut Hindu Dharma Negeri yang terletak di Jalan Ratna nomor 51 Denpasar Bali. Informan dalam penelitian terdiri atas pimpinan fakultas, kepala program studi, tenaga kependidikan, para dosen dan perwakilan mahasiswa Fakultas Dharma Acarya Institut Hindu Dharma Negeri Denpasar Bali.

Teknik pengumpulan data: a) Teknik interview, dipakai untuk mewawancarai informan. b) Teknik observasi, teknik ini dipakai untuk mengumpulkan data tentang praktik interaksi mahasiswa yang memiliki perbedaan budaya, etnis atau perbedaan lain. c) Dokumentasi, seperti dokumen tentang kurikulum, buku sumber, instrumen ujian, dan karya tulis ilmiah dosen dan mahasiswa, tata tertib kemahasiswaan Fakultas Dharma Acarya 
Institut Hindu Dharma Denpasar Bali. d) Angket, khusus data tentang sikap multikultualisme mahasiswa, data ini diubah menjadi data kuantitatif untuk mendeskripsikan sikap.

Teknik Analisis data, peneliti ini menggunakan pola Milles dan Huberman, yaitu dengan tiga alur kegiatan yang berjalan bersamaan, berlangsung secara terus menerus sampai penelitian selesai, yaitu reduksi data, penyajian data, dan penarikan kesimpulan atau verivikasi. Khusus data tentang sikap multikultural mahasisiwa yang sudah dikuantifikasikan diolah menggukan rumus statistik deskriptif, yang meliputi mean, standar deviasi, nilai tertinggi, nilai terendah dan grafik, dengan bantuan Software SPSS Versi 24.

\section{HASIL DAN PEMBAHASAN}

Visi Fakultas Dharma Acarya Fakultas Dharma Acarya adalah "Terwujudnya Fakultas Dharma Acarya yang profesional, unggul, cerdas, kompetitif dalam Pendidikan Agama, Bahasa, Teknologi dan Seni. Misinya yaitu: a) Meningkatkan profesionalisme sumber daya manusia dalam pendidikan dan keguruan yang berpijak pada nilai-nilai Agama Hindu. b) Mewujudkan sumber daya manusia dalam pendidikan dan keguruan yang bermoral, bertanggung jawab serta berdaya saing. c) Meningkatkan kualitas penyelenggaraan pendidikan dan keguruan dalam bidang agama, bahasa dan seni. d) Meningkatkan kualitas penelitian dalam pendidikan dan keguruan bidang agama, bahasa dan seni. e) Meningkatkan kualitas pengabdian kepada masyarakat dalam pendidikan dan keguruan bidang agama, bahasa, dan seni

Tujuan Fakultas Dharma Acarya: 1) Menghasilkan tenaga yang profesional dan berkualitas di bidang Pendidikan dan keguruan yang berpijak pada nilai-nilai Agama Hindu. 2) Menghasilkan sumber daya manusia dalam pendidikan dan keguruan yang bermoral, bertanggung jawab, serta berdaya saing. 3) Menghasilkan penyelenggaraan pendidikan dan keguruan dalam bidang agama, bahasa, dan seni yang berkualitas.

4) Menghasilkan penelitian dalam pendidikan dan keguruan bidang agama, bahasa, dan seni yang berkualitas. 5) Menghasilkan pengabdian kepada masyarakat dalam pendidikan dan keguruan bidang agama, bahasa, dan seni yang berkualitas.

Manajer program studi di Fakultas Dharma Acarya telah memilih konten/ materi ajar yang bisa mendukung tercapainya visi yang menurut data yang bisa dikumpulkan, ada beberapa materi yang memilki muatan nilai-nilai multikulturalisme, yaitu: kesetaraan, saling menghormati, menjaga keharmonisan interaksi dan komunikasi, pengakuan terhadap adanya perbedaan, saling menolong, tidak merugikan orang lain, tanggung jawab, piswa satuan, rukun dan damai.

Nilai Kesetaraan, dalam ajaran agama Hindu "Aku adalah Engkau dan Engkau adalah Aku" ajaran ini sangat mempengaruhi sikap semua orang Hindu Bali, karena mengakui kesamaan hak atau dengan kata lain menjunjung tinggi asas kesetaraan. (I Nyoman Linggih, Dekan Fakultas Dharma Acarya, Rabu 19 Juli 2017), juga dapat dijumpai dalam Kitab Yajurveda 40.7, yang terjemahannya adalah "Seseorang yang menganggap seluruh umat manusia memiliki atma yang sama dan dapat melihat semua manusia sebagai saudaranya, orang tersebut tidak terikat dalam ikatan dan bebas dari kesedihan. Prinsip bahwa semua manusia pada hakekatnya sama di dalam Kitab Upanisad dan merupakan mahawakya atau adagium yang tersohor dalam ajaran agama Hindu yaitu "tat tvam asi" yang 
mengandung makna "aku adalah kamu". Tat tvam asi dikemukakan dalam Kitab Chandogya Upanicad: VI.8.7; VI.9.4; VI.10.3; VI.11.3; VI.12.3; VI.13.3; VI.15.3; dan VI.16.3, berbunyi “...tat satyam, sa atma, tat tvam asi...”. Artinya adalah itulah yang benar, itulah atma, tat tvam asi (Nanduq, 2017).

Hormat menghormati merupakan ajaran tentang menghormati tamu-tamu, yang terus dilestarikan baik dalam kehidupan sehari-hari di masyarakat, antara lain "Tamu adalah Raja yang harus dihormati". Ajaran Hindu lainnya yang masih memiliki keterkaitan yaitu "tamu merupakan utusan dewa yang tidak boleh diganggu" oleh karenanya siapapun yang ke Bali akan dihormati, kecuali mereka berbuat tidak baik (Dr. I Nyoman Linggih, M.Si, Dekan Fakultas Dharma Acarya, Rabu 19 juli 2017). Tradisi 'Sistem Menyabraya' berkaitan dengan sistem mengakui bahwa semua adalah saudara berlaku di seluruh Bali (I Wayan Saputra, 2017). Sumber lain yang menegaskan bahwa Kitab Atharvaveda III.30.5 yang terjemahannya: Orang-orang yang memberikan kehormatan kepada orang tua, memiliki pikiran yang baik, penuh dengan kesejahteraan. Orang-orang tersebut menjadi satu dan semua berjalan tanpa terpisahkan. Ucapkanlah ucapan yang baik, ucapkanlah ucapan yang halus. Aku menyatukan semua manusia untuk kemakmuran dan kesejahteraan (Nanduq, 2017).

Menjaga keharmonisan interaksi dan komunikasi, dalam agama Hindu ada ajaranan "Tri Hita Karana" yang artinya, adalah orang Hindu Bali wajib melakukan hubungan harmonis antara manusia dengan Tuhannya; manusia dengan manusia; manusia dengan lingkungan. Lingkungan terdiri lingkungan manusia dan lingkungan non manusia. (I Nyoman Linggih, 2017). Penjelasan lain yang senada tentang makna
"Tri Hita Karana," artinya ada tiga hubungan yang harmonis, terdiri dari: "Parahyangan", yaitu hubungan harmonis antara manusia denga Tuhan (Brahman) atau Ida Sang Hyang Widhi Wasa, "Pamongan", artinya hubungan harmonis antara manusia dengan manusia dan "Palemahan", yaitu hubungan manusia dengan lingkungan (makhluk hidup lainnya). Ketiganya merupakan ajaran yang sangat mempengaruhi terhadap sikap multikulturalisme (I Made Arsa Wiguna, 2017).

Pengakuan terhadap adanya perbedaan, ada beberapa mata kuliah pada Fakultas Dharma Acarya yang mempunyai atau mengandung nilai-nilai multikultural, antara lain: Matakuliah Itihasa (Ramayana dan Mahabarata) dan Bhagawad Gita yang berisi tentang percakapan Krisna dan Arjuna yang dalam salah satu percakapan tersebut, Krisna menyatakan sebagai berikut: "Dengan cara apapun kau menyembah Aku akan Aku terima". Ajaran tersebut mengandung nilai- nilai multikultural/toleransi yang sangat kental, karena menerima perbedaan (I Made Arsa Wiguna, 2017). Penjelasan senada antara lain termuat dalam Kitab Bhagawadgita IV.11, yang terjemahannya: Jalan manapun ditempuh manusia kearah-Ku semuanya Ku-terima dari mana-mana semua mereka menuju jalan-Ku oh Partha (Nanduq, 2017). Juga dalam Kitab Bhagawadgita VII.21 yang terjemahannya: apapun bentuk kepercayaan yang ingin dipeluk oleh penganut agama, Aku perlakukan kepercayaan mereka sama, supaya tetap teguh dan sejahtera (Nanduq, 2017).

Nilai tolong menolong bisa ditemukan dalam riwayat ketika Krisna melihat banyak rakyat kelaparan, dia menelan sebutir beras dan semua rakyat kenyang tanpa mereka makan, ajaran ini mengandung nilai-nilai kasih sayang dan nilai-nilai senang membantu orang lain 
yang membutuhkan bantuan (I Made Arsa Wiguna, 2017). Juga dalam konsep, saling membantu "Selunglung Sebayan Take" artinya baik dalam suka maupun duka (I Wayan Mandra, 2017).

Tidak merugikan orang lain dalam Hindu ada ajaran "Manawa Sewa" atau "Madawa Sewa" artinya: melayani manusia sama dengan melayani Tuhan, atau Tuhan bersemayam pada semua makhluk atau dengan kata lain "menyakiti sesama manusia itu sama dengan menyakiti Tuhan". Ajaran ini mendorong kepada seluruh umat Hindu untuk tidak berbuat sesuatu yang bisa menyakiti/merugikan sesama umat manusia dan juga kepada binatang dan tumbuh-tumbuhan, ini salah satu faktor penting pendorong lahir dan terpeliharanya sikap multikultural di Denpasar Bali dan khususnya di kampus IHDN (I Made Arsa Wiguna, 2017). Juga bisa ditemukan dalam Kitab Atharvaveda III.30.1 sebagai berikut yang terjemahannya: wahai umat manusia, Aku memberimu sifat-sifat ketulus-ikhlasan, mentalitas (kejiwaan) yang sama dan perasaan berkawan tanpa kebencian (permusuhan), seperti halnya induk sapi mencintai anaknya yang baru lahir, begitulah anda seharusnya mencintai teman-temanmu (Nanduq, 2017).

Tanggung jawab tersirat dalam ajaran "Karma Phala", Karma artinya perbuatan, Phala artinya hasil, artinya hasil dari perbuatan manusia. Dalam kehidupan sehari-hari hal ini menjadi dasar, apapun yang mereka lakukan akan berimbas pada hasil dan hidup selanjutnya (kehidupan setelah kematian) disebut Punarbhawa, yaitu kelahiran kembali. Apakah mereka lahir kembali sebagai manusia atau menjadi binatang atau tumbuh-tumbuhan. Karma Phala mempengaruhi Punarbhawa, ini menjadi salah satu faktor yang mempengaruhi terhadap sikap toleran atau intoleran (perusakan) (I Made Arsa Wiguna, 2017).

Piswa satuan, rukun dan damai merupakan konsep "Paras Paropa Sarpanaya" artinya kita satu wadah/ide, ini mendorong untuk rukun dan damai (Wayan Sugita, Budayawan, Dosen, 2017). Demikian juga dalam Kitab Atharvaveda VII.52.1 dinyatakan bahwa "semoga kami memiliki kerukunan dengan orang-orang yang dikenal akrab dan orang-orang asing(sekali)-pun" (Nanduq, 2017). Terdapat juga dalam ajaran agama Hindu dibangun dari kesadaran akan adanya atma sebagai unsur universal dalam diri makhluk hidup. Kesadaran bahsa atman bersemayam dalam diri setiap manusia tentu akan menjadi dasar hubungan-hubungan sosial, tentu akan menghindarkan munculnya pertikaian atau permusuhan di antara sesama manusia, bahkan dengan sesama makhluk ciptaan Tuhan. Kesadaran akan atman mampu menghindarkan pertikaian atau permusuhan sebagaimana disebutkan dalam Isa Upanicad 6, yang terjemahannya: "Tetapi, ia hanya melihat atman ada pada serba makhluk dan kemudian melihat sarwa insan ada pada atman, tidak akan membenci yang lain" (Nanduq, 2017). Bahkan dalam ajaran agama Hindu, yang termuat dalam Kitab Atharvaveda III.30.4 menyebutkan, sebagaimana terjemahannya: "Wahai manusia, persatukanlah yang menyatukan semua para dewa. Aku memberikan yang sama kepadamu juga sehingga anda mampu menciptakan persatuan di antara anda" (Nanduq, 2017).

Proses Perkuliahan: a) pendekatan dan metode pembelajaran sebagian sudah menggunakan metode diskusi dan tugas kelompok sebagai bagian pendekatan kooperatif yang mendorong munculnya kerjasama dan sikap multikultural. b) Para dosen sebagai manajer pada tingkat kelas, sekaligus teladan dan pendukung nilai-nilai 
multikulturalisme berperilaku santun dan tidak pernah membedakan level atau kasta Brahmana, Kesatria, Waisya dan Sudra. Juga tidak membedakan antar soroh/klan,seperti soroh Pasek, soroh Pande, soroh Arya dan lain-lain diberlakukan sama saat di dalam kelas maupun di luar kelas. c) Fakultas Dharma Acarya memberi motivasi mahasiswa dan dosen untuk merefleksikan moral melalui membaca, menulis, berdiskusi, seminar tentang multikulturalisme, bahkan seminar nasional tentang multikultur/pluralisme.

Molyo \& Maulidah

menyebutkan bahwa dalam komunikasi antar budaya sering kali tercipta atraksi budaya. Hal ini mempengaruhi manajemen komunikasi sebab atraksi budaya terdiri dari sikap terbuka, empati, kesamaan minat, tumbuhnya kedekatan yang disebabkan oleh kebersamaan, daya tarik fisik dan keterbukaan.

Budaya kampus di Fakultas menciptakan kebudayaan moral/iklim yang positif, mengembangkan lingkungan fakultas secara menyeluruh, melalui kepemimpinan fakultas, program studi, dosen dan karyawan dilengkapi dengan aturan dan tata tertib dengan pembiasaan yang terjaga. Hasil manajemen komunikasi pendidikan multikultural tersebut pada fakultas Dharma Acarya, bisa dikelompokkan pada level manajemen yang efektif, karena sikap multikultural mahasiswa dan alumninya relatif tinggi, rincianya, sebagai berikut: jumlah yang memperoleh nilai rata-rata 4 (netral/tidak bersikap) ada $1(2 \%)$, jumlah yang memperoleh nilai 5 (memiliki sikap multikulturalisme, agak tinggi/agak setuju multikulturalisme, ada 9 (18\%). Jumlah yang memperoleh nilai 6 (memiliki sikap multikultural, tinggi/setuju multikulturalisme ada 39 (78\%), yang mendapatkan nilai 7 (memiliki sikap multikultural, sangat tinggi) ada 1 (2\%).
Faktor-faktor yang mempengaruhi Terhadap Pelaksanaan Pendidikan Multikultural Pada Fakultas Dharma Acarya Institut Hindu Dharma Negeri Denpasar Bali, adalah: a) faktor-faktor internal: pimpinan, dosen serta karyawan menjadi pendukung nilai dan sikap multikultural yang tinggi. b) Materi yang memiliki nilai-nilai multikulturalisme dalam kurikulum program studi banyak yang relevan. c) Budaya atau iklim kampus sesuai dengan nilai-nilai yang terkandung dalam konten kurikulum program studi. Sedang faktor-faktor eksternal yang terkait meliputi a) budaya masyarakat Bali sangat mempengaruhi tingginya sikap multikulturalisme melebihi pendidikan formal. b) Pembiasaan melalui upacaraupacara ritual mulai tingkat banjar sampai tingkat yang lebih besar terus dilaksanakan, yang banyak menumbuhkan gotong royong, kerjasama dan komunikasi kelompok yang membentuk suburnya sikap multikultural. c) Bali sebagai daerah wisata nasional dan internasional membuat masyarakat terbiasa berinteraksi dengan banyak orang yang sangat beragam, terbingkai dalam komunikasi antar budaya yang membuat masyarakat Bali tidak mengalami gegar budaya saat bertemu dengan budaya baru.

Kegiatan manajemen komunikasi meliputi sistem pendidikan, kredibilitas komunikator, proses komunikasi dalam pembelajaran/perkuliahan, budaya lembaga pendidikan, pesan atau konten melalui bahan ajar, sikap komunikan, nilai multikulturalisme, serta keterlibatan semua lingkungan sosial pendidikan. Internalisasi nilai multikultural dalam manajemen komunikasi pendidikan melalui strategi dalam lingkup kecil yaitu di tingkat kelas dan lingkup besar di tingkat Universitas dan lingkungan pendidikan. 


\section{PENUTUP}

\section{Simpulan dan Saran}

Manajemen komunikasi pendidikan multikultural di Fakultas Dharma Acarya Institut Hindu Dharma Negeri Denpasar Bali, merupakan bagian tak terpisahkan dari keseluruhan pengelolaan pendidikan, penelitian dan pengabdian kepada masyarakat, yang merupakan wujud kreativitas dan seni dalam melahirkan alumni yang ideal. Strategi manajemen komunikasi pendidikan multikultur adalah meliputi sistem pendidikan, kredibilitas komunikator, proses komunikasi perkuliahan, budaya lembaga pendidikan, konten bahan ajar, sikap komunikan, nilai multikulturalisme, serta keterlibatan semua lingkungan sosial pendidikan.

Langkah-langkah untuk mewujudkan strategi manajemen komunikasi pendidikan meliputi tentang; a) sistem pendidikan yang berpijak pada nilai Agama Hindu yang banyak mengandung nilai multikulturalisme. b) Pemilihan materi/konten pembelajaran bersinggungan dengan multikulturalisme, meliputi: nilai kesetaraan, saling menghormati, keharmonisan dalam berinteraksi dan berkomunikasi, pengakuan perbedaan, saling menolong, tidak merugikan orang lain, bertanggung jawab, menjaga persatuan, rukun dan damai. c) Pendekatan dan metode pembelajaran sudah menggunakan metode diskusi dan tugas kelompok sebagai bagian pendekatan kooperatif yang mendorong munculnya kerjasama dan sikap multikultural. d) Para dosen sebagai manajer pada tingkat kelas, sekaligus teladan dan pendukung nilai-nilai multikulturalisme mengelola model komunikasi dan berperilaku santun dan tidak pernah membedakan level atau kasta Brahmana, Kesatria, Waisya dan Sudra. Juga tidak membedakan antar soroh/klan. e) Fakultas Dharma Acarya memberi motivasi mahasiswa dan dosen untuk merefleksikan sikap multikultural melalui membaca, menulis, berdiskusi, seminar. f) Menciptakan budaya/iklim kampus yang mengandung nilai-nilai multikulturalme yang positif, mengembangkan lingkungan fakultas secara menyeluruh. g) Hasil upaya pengelolaan pendidikan multikultural pada fakultas Dharma Acarya, dikelompokkan pada level manajemen yang efektif, karena sikap multikultural mahasiswa dan alumninya relatif tinggi.

Komunikasi antara alumni, mahasiswa dan civitas pendidikan lainnya sangat efektif dan memiliki kecenderungan yang tinggi dalam manajemen komunikasi pendidikan multikultural. Sebesar 78\% memiliki sikap multikultural dan setuju terhadap nilai multikulturalisme. Hal ini didukung oleh faktor internal dan eksternal dimana keduanya berkaitan dengan menajemen komunikasi organisasi. Faktor internal berkaitan dengan komunikator pendidikan, pesan yang berupa materi perkuliahan berkaitan dengan multikulturalisme, budaya atau iklim kampus yang beririsan dengan multikulturalisme. Sedang faktor eksternal, meliputi: budaya masyarakat Bali pembiasaan melalui upacara-upacara ritual mulai tingkat banjar sampai tingkat yang lebih besar dan kebiasaan interaksi masyarakat Bali dengan budaya asing.

\section{DAFTAR PUSTAKA}

Aly, Abdul. (2010). Pendidikan Islam Multikultural di Pesantren Telaah Terhadap Kurikulum Pondok Pesantren Modern Islam Assalam Surakarta. Yogyakarta: Pustaka Pelajar.

Arends, Richard I. (2008). Learning To Teach, Terj. Helly Prajitno Soetjipto 
dan Sri Mulyantini Soetjipto. Yogyakarta: Pustaka Pelajar.

Behman, Magdy B. (2017). Defining a Role of Intercultural Islamic Education for Religious Deradicalization. Makalah dalam International Seminar on Islamic Civilization, Wonosobo.

Block, K \& Gibbs, L., Macfarlane, S \& Townsend, M. (2015). Promoting Appreciation of Cultural Diversity and Inclutsionn with the Stephanie Alexander Kitchen Garden Program. Journal for Multicultural Education, Vol 9 (1) pp 2-9

Blythe, Laura, dkk. (2014). Technological Innovation in Twenty-First Century Multicultural Teacher Preparation, Journal for Multicultural Education, Vol. 8 Iss 1 pp. $54-67$

Cousik, R. (2015). Cultural and Functional Diversity in the Elementary Classroom: Strategies for Teachers. Journal for Multicultural Education, Vol. 9 (2) pp 54-67.

Gasman, Marybeth., Commodore, Felecia. (2014). The State Of Research On Historically Black Colleges And Universities. Journal for Multicultural Education, Vol. 8 Iss 2 pp. $89-111$.

Harris, Reily. (2000). Demokrasi dan Konflik Yang Mengakar: Sejumlah Pilihan untuk Negosiasi, Jakarta: AMEEPRO.

Hecht, Ana Carolina. (2014). An analysis of intercultural bilingual education in Argentina. Journal for Multicultural Education, Vol. 8 Iss 2.
Kartadinata, Sunaryo. (2015). Pendidikan Kedamaian. Bandung: Remaja Rosdakarya.

Liliweri, Alo. (2007). Makna Budaya dalam Komunikasi Antarbudaya. Yogyakarta: LKiS.

Mahfud, Choirul. (2006). Pendidikan Multikultural. Yogyakarta: Pustaka Pelajar.

Maydosz, Ann S. (2014). Disproportional Representation of Minorities in Special Education. Journal for Multicultural Education, Vol. 8 Iss 2 pp. $81-88$.

Murad, Ahmad Raza Hasan Sohaib. (2014). Learning in plural cultural context. Journal for Multicultural Education, Vol. 8 Iss 1 pp. 2 - 12 .

Molyo, P. D., \& Maulidah, F. (2018). Atraksi Interpersonal Pada Komunitas Beda Agama. Jurnal Nomosleca, 4(1).

Nanduq, Ferdinandus. (2017). "Pendidikan Agama dalam Konstruksi Pemikiran Global, Bertindak Lokal dan Menghargai Pluralisme" PROSIDING, Seminar Nasional di Fakultas Dharma Acarya, Institut Hindu Dharma Negeri Denpasar.

Pidarta, Made. (2004). Manajemen Pendidikan Indonesia. Jakarta: Rineka Cipta.

Prami, Anak Agung Istri Ngurah Dyah. (2014). Meningkatnya Intensitas Konflik desa Pakraman di Bali. Jurnal Ilmiah Sosiologi SOROT Vol 1, No 2 http://ojs.unud.ac.id/index.php/sorot/ article/viewFile/9447/6986. 
Ritu, Dangwal Krati., Hazarika, Sharma Santonu. (2014). Hole-In-The-Wall Learning Stations and Academic Performance Among Rural Children In India. Journal for Multicultural Education, Vol. 8 Iss 1 pp. 31 - 53

Robbins, Stephen P., Judge, Timothy A. (2008). Perilaku Organisasi, Edisi 12, Jakarta: Salemba Empat.

Suaedy, Ahmad., dkk. (2007). Politisasi Agama Dan Konflik Komunal. Jakarta: Penerbit The Wahid Institute.

Sule, Ernie Tisnawati., Saefullah, Kurniawan. (2006). Pengantar Manajemen. Jakarta: Prenada Media.

Sunu, I Gusti Ketut Arya., dkk. (2014). Harmonisasi, Integrasi Desa Pakraman dengan desa Dinas yang multietnik dan multiagama menghadapi pergeseran, pelestarian, dan konflik di Bali. Jurnal Ilmu Sosial dan Humaniora (JISH) Undiksha.Vol 3, No2 http://ejournal.undiksha.ac.id/index. php/JISH/article/viewFile/4469/ 3442

Somaraki, Maria., dkk. (2016). Controlling Feeding Practices and Maternal Migrant Mackground: An Analysis of A Multicultural Sample. Public Health Nutrition Journal, Vol 20 (5) pp. 848-858. Cambrige.

Wirutomo, Paulus., dkk. (2012). Sistem Sosial Indonesia. Jakarta: UI Press.

$\mathrm{Xu}$, Yaoying., Hao, Chenfang., Huennekens, Mary Ellen. (2016). Effect of a Multicultural Perspectives Course on Teacher Candidates' Intercultural Competence. Journal of Multicultural Education Vol. 10 No.1 72-86.
Commonwealth University, Richmond, Virgina, USA.

Yoo, Sungae., dkk. (2014). Antara Ideal Dan Realitas. Journal for Multicultural Education, Vol. 8 Iss 1 pp. $13-30$.

\section{Sumber lain :}

http://antaranewsbali.com. 29 September 2018. Diakses 23 Nopember 2018.

http://nusabali.com 2 Mei 2017. Diakses 23 Nopember 2018.

http://sindonews.com. 22 Januari 2017. Diakses 23 Nopember 2018.

http://tempodenpasar.com. 17 Desember 2015. Diakses 23 Nopember 2018.

http://vivanews.com. 19 juli 2011. Diakses 23 Nopember 2018.

Windia, Wayan P. (2010). Konflik Antardesa Pekraman Bali Terjadi 112 Kali. http://www.antarabali.com/print/331 3/konflik-antardesa-pekraman-baliterjadi-112-kali. Diakses 26 Februari 2017 